leee Journal Of Selected Topics In Applied Earth Observations And Remote Sensing

November 2016, Volume 9 Issue 11 Pages 5209-5222

Achimer

http://dx.doi.org/10.1109/JSTARS.2016.2533662

http://archimer.ifremer.fr/doc/00363/47462/

(c) 2016 IEEE. Personal use is permitted, but republication/redistribution

requires IEEE permission. See

http://www.ieee.org/publications_standards/publications/rights/index.html

for more information.

\title{
Geostationary Image Simulation on Coastal Waters Using Hydrodynamic Biogeochemical and Sedimentary Coupled Models
}

\author{
Lei Manchun ${ }^{1,2}$, Minghelli Audrey ${ }^{1,2}$, Fraysse Marion ${ }^{3,4}$, Pairaud Ivane $^{5}$, Verney Romaric ${ }^{6}$, \\ Pinazo Christel ${ }^{3,4}$
}

${ }^{1}$ Aix Marseille Univ, CNRS, LSIS UMR 7296, ENSAM, F-13397 Marseille, France.

2 Univ Toulon \& Var, CNRS, LSIS UMR 7296, F-83957 La Garde, France.

${ }^{3}$ Aix Marseille Univ, CNRS INSU, IRD, MIO,UM 110, F-13288 Marseille, France.

${ }^{4}$ Univ Toulon \& Var, CNRS INSU, IRD, MIO,UM 110, L-83957 La Garde, France.

${ }^{5}$ IFREMER, LER PAC, F-83507 La Seyne Sur Mer, France.

${ }^{6}$ IFREMER, DYNECO PHYSED, F-29280 Plouzane, France.

Corresponding authors : email addresses : manchun.lei@univ-tln.fr ; audrey.minghelli@univ-tln.fr ; marion.fraysse@univ-amu.fr ; ivane.pairaud@ifremer.fr ; romaric.verney@ifremer.fr ; christel.pinazo@univ-amu.fr

\begin{abstract}
:
This study proposes a method to simulate the images of the future European geostationary sensor dedicated to ocean color sensor: the geostationary ocean color advanced permanent imager (GeoOCAPI), and it demonstrates the sensor capabilities to monitor the water composition throughout the day. The temporal variation of the coastal seascape is obtained from biogeochemical and hydrosedimentary models, the ocean-atmosphere radiance is obtained from the water and atmosphere radiative transfer model. The GeoOCAPI images are simulated with 400-m resolution, 18 spectral bands with associated signal-to-noise ratio (SNR) and with 1-h acquisition frequency, on the Gulf of Lion (Marseille, France) during a pollution event caused by the urban outfall of Cortiou in Marseille. These images describe the water color dynamic in the Gulf of Lion due to the river transport and the urban outfall. The validation with real medium resolution imaging spectrometer (MERIS) images showed that the image simulator was reliable with an average relative error (RE) at $4.76 \%$ for visible bands and at $16.51 \%$ for near infrared bands. The quasi-analytical algorithm (QAA) inversion method was tested. The suspended particulate matter (SPM) and the colored dissolved organic matter (CDOM) can be retrieved with good accuracy; the error is, respectively, $7.69 \%$ and $12.21 \%$. The chlorophyll concentration (chl) is misestimated $(58.10 \%)$ due to the low concentration in this area $(<1 \mathrm{mg} \cdot \mathrm{m}(-3))$ compared to SPM (> $1 \mathrm{~g} \cdot \mathrm{m}(-3))$. The study showed that the future geostationary sensor GeoOCAPI will be able to monitor
\end{abstract}


the water composition in coastal areas through the day and detect and monitor an urban outfall discharge.

Keywords : Geostationary ocean color advanced permanent imager (GeoOCAPI), geostationary orbit, image simulation, ocean color 


\section{Introduction}

In coastal waters, many challenging issues such as the sediment transport dynamics, the land/ocean interaction, the water quality degradation or the harmful algal blooms, are often unpredictable, with a high temporal dynamics. Such phenomena then require a high frequency image acquisition with a high sensitivity to water color and a moderate spatial resolution [1].

The sun-synchronous Low Earth Orbit (LEO) mission, such as SeaWiFS, MODIS and MERIS are currently used for the water quality survey but their temporal resolution (at most 1 image/day) is often limited for such coastal applications [1]. The Geostationary Earth Orbit (GEO) solution can provide a high revisit frequency. Neukermans et al. proved the feasibility of mapping the diurnal Total Suspended Matter (TSM) cycle in turbid waters using a meteorological sensor like SEVIRI on Meteosat Second Generation [2] and extended the use of SEVIRI sensor to the turbidity and light attenuation mapping [3]. The first and still unique geostationary ocean color sensor, the Geostationary Ocean Color Imager (GOCI) [4] was launched in 2010 by the South Korean spatial agency and operated by the Korean Ocean Satellite Center (KOSC). GOCI provides 8 channels from 412 to 865 $\mathrm{nm}$ with an hourly temporal resolution during daytime (8 images per day) and a medium spatial resolution $(500 \mathrm{~m})$. GOCI covers a local area of $2,500 \mathrm{~km} \times 2,500 \mathrm{~km}$ centered on the Korean peninsula $\left(130^{\circ} \mathrm{E}, 36^{\circ} \mathrm{N}\right)$. The recent studies [5]-[9] showed that the GOCI's ocean color data can be used for the monitoring of diurnal change of the optical properties, suspended matter, turbidity and harmful algal bloom, even in this cloudy region because one image/hour allows to make composite images to be made without clouds.

In Europe, there is also an ongoing project to launch a water color sensor on a geostationary orbit. GeoOCAPI is a geostationary project dedicated to ocean color, conducted by the French Spatial Agency (CNES) and planned to be launched around 2020. This mission is designed to provide hourly observations with moderate spatial resolution $(250 \mathrm{~m}$ at the equator) over the Atlantic Ocean, the Mediterranean Sea, the European and African coastal zones (full disk) from a geosynchronous orbits at longitude $10^{\circ} \mathrm{W}$ [10], with 18 bands in the $395-1020 \mathrm{~nm}$ range (Table 1. O). The Signal to Noise ratio is high (around 400) in order to be sensitive enough to detect very weak surface reflectance variations.

\section{[Insert table 1 about here]}

Compared to MERIS, the Medium Resolution Imaging Spectrometer, with 300 m resolution 15 spectral bands and a temporal revisit of 3 days, the spatial and spectral resolution will be similar but the main change will be to the temporal revisit (1 image/hour). Compared to MODIS, the spatial and temporal resolution will be improved with GeoOCAPI. Compared to GOCI, the African/European face will be imaged with a much better coverage because the full disk will be covered.

In this study, our goal is to simulate images of the future geostationary sensor GeoOCAPI in order to evaluate the potential of GEO sensors compared to a LEO sensor for the monitoring of water quality. The site of the Gulf of Lion (France) was chosen for the diversity of problems caused by the Rhone River mouth and the urban outfall of Cortiou.

Different approaches for image simulation were possible. The first one is based on the spatial and the spectral degradation of high spatial and spectral resolution image, according to the features of the instrument (with MERIS [11] and Thematic Mapper [12]). This approach cannot lead to the simulation of a geosynchronous image because the spatial coverage would be too low and the viewing and solar angles are not representative of the geosynchronous configuration. A second approach is the 
forward model, which consists of modeling the surface reflectance and the radiance at the top of the atmosphere, as a function of ground biophysical and geometrical parameters [13]-[15]. The first advantage of this approach is that the models take into account the viewing and solar angles, which are important for non-Lambertian surface like the ocean. The second advantage is the availability of ground truth (concentration maps) to validate algorithms of water composition estimation for example. Once the image is simulated, generic algorithms for chlorophyll $(\mathrm{chl})$ or Suspended Particulate Matter $(S P M)$ concentration estimation can be applied and preliminary validation is possible thanks to the input maps. Therefore this latter approach was chosen in this study to simulate geostationary images.

In a previous study, a Geosynchronous ocean color image simulator was developed in order to analyze the influence of the illumination and viewing geometries variability on the radiometry [16]. The simulator combines the water radiative transfer model Hydrolight and the atmosphere radiative transfer model MODTRAN to simulate the light transfer process downward from the sun to the water and upward from the water to the sensor. The bio-optical data from GlobColour level 3 were used as input maps in order to simulate the hourly global area coverage images during a day. The simulator was effective for directional radiance image simulation and for angular effect analysis but it could not simulate images on coastal area with diurnal dynamics because the water composition data was provided by the ocean color products which do not provide the high temporal resolution.

In this study our objectives are (1) to extend the simulator to the coastal dynamics simulation, such as river sediment transport and urban outfall discharge, (2) to improve the accuracy of the radiometric image simulation, and (3) to evaluate the potential of the GeoOCAPI mission for monitoring of the water quality change in coastal area.

In this paper, we first introduce the methodology used to simulate geostationary images in coastal waters (section 2). We detail the models used to characterize the water composition evolution during the day and the models used to simulate the spectral radiance at the sea surface, at the top of the atmosphere (TOA) and the radiance measured by the sensors according to its spectral and SNR features. Then we present the results of image simulation, the validation results (section 3) and finally, we discuss the potential of the future geostationary GeoOCAPI sensor compared to a LEO sensor like MERIS for monitoring the change of water quality in the Gulf of Lion (section 4) and we conclude (section 5).

\section{Methodology}

In this section, we present our methodology to simulate geostationary images: The choice of the study area, where temporal seascape models are available. We describe these models and define a period of simulation. Then we explain how the sea surface reflectance image can be simulated with the water radiative transfer model and we describe the atmospheric model in order to obtain Top of Atmosphere radiance. Finally the sensor model is presented in order to take into account the sensor features and to provide the simulated images. An inversion method (QAA) is proposed to estimate the water components from the simulated images.

\subsection{The study area}

In this study, we focus on two different continental sources: the Rhone River ROFI (Region of Fresh water Influence) and an urban outfall. The spatial scale of these two sources are different: the Rhone plume covers between 10 and $100 \mathrm{~km}^{2}$ while the Cortiou outfall plume covers less than $10 \mathrm{~km}^{2}$. These 2 sources are very sensitive to meteorological conditions (rainfall and wind) and hydrological conditions (hydrology). 
[Insert Figure 1 about here]

Figure 1 shows the geographic location of the Gulf of Lion on geostationary projection map as will be viewed by the GeoOCAPI sensor. The nadir spatial resolution of GeoOCAPI is $250 \mathrm{~m}$, but because the pixel size increases with the sensor zenithal angle, the pixel size in this area will be around the $400 \mathrm{~m}$.

\subsection{Temporal seascape modelling and period of simulation}

The temporal variability of the water composition (here $c h l$ and SPM) is obtained by models. The hydrodynamic ocean model MARS3D (3D hydrodynamic Model for Application at Regional Scale, IFREMER) [17] was used in its RHOMA (Rhône-Marseille) configuration, forced by the atmospheric model MM5 $\left(5^{\text {th }}\right.$ generation PSU/NCAR mesoscale model, providing pressure, humidity and $W_{\text {spd }}$ data). It was used to model the advection of particles and the advection and diffusion of biogeochemical tracers from the input sources (Rhone River, Marseille city urban inputs, atmosphere...) to the open sea. The input data of this model are: the water river contribution, the liquid input from the Waste water Treatment Plant contributions, meteorological parameters (pressure, wind speed and direction, air temperature, rainfall, heat fluxes). Hydrodynamic initial and open boundary conditions at the south and west border issued from the MENOR model [18]. The model was validated for year 2007 and 2008 [19].

MARS3D (RHOMA) was coupled with a numerical Hydro-Sedimentary model (hereafter called MS model) described in [20] in order to model the sediment dynamics in the Gulf of Lion, taking into account the liquid and solid outflow from the Rhone River, the coastal rivers and the Cortiou outfall. The input data of this model are, in addition to the hydrodynamic model: the solid input from rivers and Waste water Treatment Plant and the Wave shear stress from the WW3 model orbital velocity [20] used to compute the erosion and deposit of particles at the sea bed. All details about the model processes, input and output can be found in the literature[19]-[21].

This model provides hourly non-organic Suspended Particle Matter $\left(S P M_{\text {norg }}\right)$ maps at each model grid cell, with $400 \mathrm{~m}$ spatial resolution and 30 vertical levels (3D model).

MARS3D (RHOMA) was also coupled with the ECO3M model (Ecological Modular Mechanistic Model)[22], [23], in its MASSILIA (Bay of Marseille) configuration, hereafter called ME model, designed to model the biogeochemical carbon, nitrogen and phosphorus cycles of aquatic ecosystems and validated for year 2007 and 2008[21], [24].

The input data of this model are, in addition to those for hydrodynamics: the rivers and Waste water Treatment Plant biogeochemical contributions (nutrients), the nutrient input from the atmosphere, and biogeochemical conditions from the GoL model [24] focused on the Gulf of Lion.

This model provides hourly chl and Particulate Organic Carbon (POC) maps with $400 \mathrm{~m}$ spatial resolution and 30 vertical levels (3D models). The water column is divided into 30 levels. Intervals then depend on the water depth. But even for a given depth, the intervals are not constant along the water column, the vertical intervals are refined close to the surface and to the bottom. For a better description of the bottom and numerical advantages such as a constant number of levels, Philipps (1957) introduced normalized depth [25]. This vertical coordinate system, known as terrain-following coordinates, is used by numerous models for both ocean and shelf modeling. 
In order to choose an interesting period to study the $S P M$ discharge, we visualized the MERIS images chowing a $S P M$ discharge at the Cortiou outfall. This period was fixed between 13 and 23 May 2008. Then the ME and MS models were computed and we cheeked that the plume showed up on the two maps (MERIS and model). Figure 2 shows that a discharge from the Cortiou outfall was effectively measured by MERIS (Figure 2.1) and simulated by MS model (Figure 2.2).

\section{[Insert Figure 2 about here]}

On these maps, the SPM concentration is higher with the model (around $3 \mathrm{~g} \cdot \mathrm{m}^{-3}$ ) than with the MERIS SPM map, but the objective is not to validate the model with the MERIS product. Area close to the coastal areas are particularly complex. The model is a simplification of the reality, hypothesis are made. For example, the Waste water Treatment Plant provides only the output flow every 6 minutes, but hypotheses are formed in the model on the SPM concentration and on the particle size which are not provided by the treatment plant. For example, the SPM concentrations at the Cortiou outfall are supposed to be constant equal to $40 \mathrm{~g} \cdot \mathrm{m}^{-3}$ and the particle size are assumed to be $50 \%$ heavy and 50\% light. Heavy particle sink faster than the light ones. So, these assumptions may not correspond to the reality and they can explain the differences between simulated images and real images. Nevertheless, we compared in different locations the $S P M$ concentrations provided by the MERIS product with those provided by the model. On the Rhone plume, the concentrations are similar, fluctuating between 4 and $10 \mathrm{~g} \cdot \mathrm{m}^{-3}$ for the 2 maps. In the clear waters, far from the plume, the concentrations are around $1.2 \mathrm{~g} \cdot \mathrm{m}^{-3}$ for the model and $0.2 \mathrm{~g} \cdot \mathrm{m}^{-3}$ for the image.

The 3D water composition maps of chl, POC and SPMnorg were converted into 2D maps by integration of concentration along a vertical profile. We know that the influence of the vertical profile of the water composition on the water surface reflectance can be described by a decreasing exponential function depending on depth [26], [27]. The slope of this exponential function depends on the light attenuation coefficient $K_{d}$. The influence of the vertical profile decreases with the turbidity at surface level. Zaneveld and al. [27] proposed a function $\mathrm{g}(\mathrm{z})$ defined by parts calculated from the down-welling irradiance at a given depth. As Hydrolight provides this information, we can calculate the $\mathrm{g}(\mathrm{z})$ function coefficients. For these simulation, we used the Inherent Optical Properties (IOPs) corresponding to the Mediterranean Sea and we carried out several simulations by varying the components concentration from low to high. Finally we provide $\mathrm{g}(\mathrm{z})$ for water in low, medium and high concentration. We determined 3 weighting depth average functions [27] depending on the surface water composition.

$$
g(z)=\left\{\begin{array}{cc}
E X P(-0.15 z-1.81) & \text { if } c h l \leq 0.4 \mathrm{mg} \cdot \mathrm{m}^{-3} \text { and } S P M_{\text {norg }} \leq 2.0 \mathrm{~g} \cdot \mathrm{m}^{-3} \\
\operatorname{EXP}(-0.84 z-0.67) & \text { if } \mathrm{chl} \geq 5.0 \mathrm{mg} \cdot \mathrm{m}^{-3} \text { and } S P M_{\text {norg }} \geq 10.0 \mathrm{~g} \cdot \mathrm{m}^{-3} \\
\operatorname{EXP}(-0.41 z-0.98) & \text { else }
\end{array}\right.
$$

The concentration at the sea surface level $\left(C_{\text {surf }}\right)$ is obtained from (2):

$$
C_{\text {surf }}=\frac{\sum C(z) g(z)}{\sum g(z)}
$$

Where $C(z)$ is the concentration of $c h l, P O C$ or $S P M_{\text {norg }}$ and $\mathrm{g}(\mathrm{z})$ the depth average function (1).

Because the next step requires $S P M$ maps, we needed to obtain Suspended Organic Matter $\left(S P M_{\text {org }}\right)$ maps that ban be deduced from POC map [28]:

$$
S P M_{\text {org }}=2.6 P O C
$$


The $S P M_{\text {norg }}$ is directly obtained from the MS model, and the SPM is then obtained by the sum of organic and non-organic suspended matter:

$$
S P M=S P M_{\text {org }}+S P M_{\text {norg }}
$$

Because any available model provides the $C D O M$ 3D maps, we tried to deduce this information from another source. Babin et al. [29] studied the relation between CDOM vs. SPM and chl., in case 2 waters, with in situ measurements. They showed that $a_{y}(443)$ co-varies with $S P M$ and $c h l$. In their article, in Mediterranean sea, the ratio $a_{y}(443) / S P M \approx 0.066$ and the ratio $a_{y}(443) / c h l \approx 0.1$. With MERIS images acquired in May 2008 in the Gulf of Lion (our study), we also noticed a covariation: $a_{y}(442) / S P M=0.0633$ (with $\mathrm{R}^{2}=0.96$ ) and $a_{y}(442) / c h l=0.092$ (with $\mathrm{R}^{2}=0.87$ ). We noticed that the relations were similar from one study to the other. We chose to keep the ratio given by MERIS because MERIS image was acquired on the study area and during the simulation period. We chose also the relation between $a_{y}(442)$ and $S P M$ because $\mathrm{R}^{2}$ is higher with $S P M$ than with chl. This empirical function is then used to calculate the $C D O M$ maps from the $S P M$ maps.

Figure 3 shows the $c h l$ and SPM concentration maps provided by the coupled models at the sea surface on 18 May 2008 at 10:00 am.

[Insert Figure 3 about here]

On Figure 3, we notice a high chlorophyll concentration in the Gulf of Fos (North) and along the coast. On the SPM map the highest concentration is located at the Rhone River mouth and along the coast of Marseille. The Cortiou outfall discharge is once more visible on this map.

\subsection{IOPs calculation and Water reflectance image simulation}

The total absorption coefficient $a$, total scattering coefficient $b$, and the backscattering coefficient $b_{b}$ depend on the contributions of the different water components.

$$
\begin{aligned}
& a=a_{w}+a_{\emptyset}+a_{y}+a_{\text {nap }} \\
& b=b_{w}+b_{p} \\
& b_{b}=0.5 b_{w}+b_{f p} b_{p}
\end{aligned}
$$

where $a_{w}$ is the pure seawater absorption coefficient, given from [30]-[32], $a_{\phi}$ is the phytoplankton absorption coefficient, $a_{y}$ is the absorption coefficient of CDOM, $a_{n a p}$ is the non-algal particle absorption coefficient, $b_{w}$ is the pure seawater scattering coefficient, given from [33], $b_{p}$ is the water particle scattering coefficient and $b_{f p}$ is the water particle backscattering fraction, given as 0.0183 [34], [35].

The phytoplankton absorption coefficient $a_{\phi}$ is calculated as a function of $c h l$ and the $c h l$ specific absorption coefficient $a_{\phi}^{*}$ [36], [37].

$$
a_{\phi}(\lambda)=a_{\phi}^{*}[\operatorname{chl}]
$$

$a_{\phi}^{*}$ is provided by Bricaud et al. [37]. This result is based on 815 samples measured in several oceanic areas of the world, including 67 samples measured in the Mediterranean (Mediprod 6 
campaign in 1990). The measuring area is located in the rectangle defined by longitude between $0^{\circ} \mathrm{E}$ and $6^{\circ} \mathrm{E}$ and latitude between $36^{\circ} \mathrm{N}$ and $40^{\circ} \mathrm{N}$ (Southern Golf of Lion). The chl range of measurement is $\left[0.06-7.5 \mathrm{mg} \cdot \mathrm{m}^{-3}\right]$, it covers therefore the most simulated $\mathrm{chl}$ concentrations.

The non-algal particle absorption coefficient $a_{\text {nap }}$ is related to $S P M$ [29]:

$$
a_{\text {nap }}(\lambda)=0.036[S P M] \exp [-0.0123(\lambda-442)]
$$

The calculation of $a_{\text {nap }}$ is provided by Babin et al. [29] based on 6 measurement campaign "Coastal Surveillance Through Observation of Ocean Color". Among the 387 measurement stations 63 are located in the Golf of Lion, including the Rhône River mouth (campaign 2 and 4). $a_{\text {nap }}$ from equation (9) is then derived from 2 constant values. The first $a_{n a p}(442 \mathrm{~nm})=0.036[S P M]$ is given by Babin et al. for the Mediterranean [29]. The second is the $a_{\text {nap }}$ spectral slope $=0.0123 \mathrm{~m}^{-1}$.

The $C D O M$ absorption coefficient $a_{y}$ is calculated by the following equation [29]:

$$
a_{y}(\lambda)=a_{y}\left(\lambda_{0}\right) \exp \left[-0.017\left(\lambda-\lambda_{0}\right)\right]
$$

Where $a_{y}\left(\lambda_{0}\right)$ is the $C D O M$ absorption coefficient at $442 \mathrm{~nm}$.

The particle scattering coefficient $b_{p}$ is described as a power function, the specific factor for Mediterranean waters is given by[28].

$$
b_{p}(\lambda)=0.42[S P M]\left(\frac{\lambda}{555}\right)^{-0.2}
$$

As described by Lei et al. [16], the numerical radiative transfer models cannot be used for each pixel simulation because the simulation of the whole image would be too time consuming. The Hydrolight version 5 [38] was used in this study to build the Look-Up-Table (LUT) of the direct surface reflectance $\left(R_{r e f l}\right)$ and the remote sensing reflectance $\left(R_{r s}\right)$, related to the IOPs (especially nonwater absorption coefficient $a_{n w}=a-a_{w}$, and particle scattering coefficient $b_{p}$ ), the geometric angles (sun zenith angle $\theta_{s}$, sensor zenith angle $\theta_{c}$, and relative azimuth angle $\Delta \phi$ ) and the wind speed ( $W_{s p d}$ ). The Hydrolight simulation was performed in "IOP data" mode in order to determine the relationship between $R_{r s}$ and the IOPs.

\subsection{Top Of Atmosphere radiance image simulation}

The TOA radiance was calculated according to the four-stream radiative transfer theory [14]. It results from 3 contributions: the atmospheric reflection, the direct target reflection and the surface environmental reflection.

$$
L_{T O A}=\frac{E_{s} \mu_{s}}{\pi}\left[\rho_{a t m}+\frac{T_{S}}{1-\rho_{e} S}\left(T_{\text {dir }} \rho+T_{\text {dif }} \rho_{e}\right)\right]
$$

where $E_{s}$ is the extraterrestrial solar irradiance, $\mu_{s}$ the cosine of sun zenith angle, $\rho_{\text {atm }}$ the atmosphere intrinsic reflectance (molecular + aerosol), $S$ the atmosphere spherical reflectance, $T_{s}$ the total downwelling transmittance from the sun to the target, $T_{d i r}$ the direct upwelling transmittance, $T_{\text {dif }}$ the diffuse upwelling transmittance, $\rho$ the target surface reflectance and $\rho_{e}$ the environmental surface reflectance. 
In equation (12), the surface reflectance $\rho$ is considered as $\pi R_{r s}$. For each pixel, $\rho$ value is calculated from a multi-interpolation of $R_{r s}$ LUT. The environmental surface reflectance $\rho_{e}$ is considered as $\pi R_{\text {refl }}$. Its value is calculated through multi-interpolation with the $R_{\text {refl }}$ LUT. The other radiometric parameters $\left(E_{s}, \rho_{a t m}, S, T_{s}, T_{d i r}\right.$ and $\left.T_{d i r}\right)$ can be obtained directly from $6 \mathrm{~S}$ model [39] or from the MODTRAN model [40] and we chose the last for this study. The maritime aerosol profile proposed by MODTRAN was chosen because the visibility and relative humidity of this model are the closest to the local atmospheric conditions.

The meteorological parameters (temperature, pressure, humidity, and aerosol) inputs of atmospheric model, were given by the Meteorological Model (MM5). The LUTs and their dependency on input parameters are presented in Table 2.

[Insert Table 2 about here]

\subsection{The sensor simulation}

Concerning the spectral bands, we integrated the simulated reflectance over GeoOCAPI spectral bands considered as square response (Table 1).

The GeoOCAPI spatial resolution will be $250 \mathrm{~m}$ at the equator, but for geometric reasons, at latitude $43^{\circ}$ and longitude $3^{\circ}$, resolution becomes $380 * 410 \mathrm{~m}$, in the Gulf of Lion latitude. Because the spatial horizontal resolution of the model output maps is $400 \mathrm{~m}$, the resolution of the simulation is consistent.

The three main sources of noise for the sensor are divided into 3 main categories: the photonic noise, the read noise and quantization noise. The two last noises can be neglected thanks to the high quality of the electronic components and to the high quantization resolution of GeoOCAPI (12 bits). The photonic noise is the most important, proportional to the number of photons captured. The flux of photons received is subject to a Poisson process, and therefore the noise is proportional to the signal square root. This noise is considered to be Gaussian, with a standard deviation $\sigma_{p h}=\sqrt{\alpha_{p h} \times L_{T O A}}$.

The signal to noise ratio (SNR) represents the importance of all the noises relative to the signal. This ratio depends on the amplitude of the signal and can also vary with the wavelength. The total noise can be considered as a white Gaussian noise with a standard deviation $\sigma_{b}(13)$.

$$
\sigma_{b}=\sqrt{\alpha_{p h} \times L_{T O A}}=\frac{\sqrt{L_{T O A} \times L_{r e f}}}{S N R}
$$

$L_{r e f}$ and SNR are given in Table 1, depending on the spectral bands. This noise is added on the Top Of Atmosphere radiance images.

$$
L_{T O A}^{b}=L_{T O A}+N\left(O, \sigma_{b}{ }^{2}\right)
$$

where $N\left(0, \sigma_{b}{ }^{2}\right)$ is a white Gaussian noise with 0 mean and $\sigma_{b}^{2}$ variance. The added value is different for all the pixels of the image.

\subsection{Water composition estimation}

In order to monitor the water composition during the day, we applied to the simulated image, the inversion algorithm based on the Quasi-Analytical Algorithm (QAA) [41], [42]. By the means of the minimization between the simulated spectrum and a reflectance model, we can estimate the water composition (chl, SPM and CDOM) in order to evaluate the influence of the noise on the water 
composition estimation and to show the geostationary capability to monitor the water composition during the day.

The QAA model considers that the remote sensing reflectance can be contributed by the deep water, the water column and the bottom reflectance. In our study case, the water depth was considered as infinite, so we just use the deep water contribution to model the remote sensing reflectance $R_{r s}$.

$$
\begin{aligned}
& R_{r s}=\frac{0.518 r_{r s}^{d p}}{1-1.562 r_{r s}^{d p}} \\
& r_{r s}^{d p}=(0.084+0.0794 u) u \\
& \text { with } \quad u=\frac{b_{b}}{a+b_{b}}
\end{aligned}
$$

where $r_{r s}^{d p}$ is the remote-sensing reflectance for optically deep water, $a$ is the total absorption and $b_{b}$ is the total backscattering coefficient.

We validated equation (15) obtained from modified QAA model with in-situ measurement from Optic-Med project [43]. Optic-Med data contains IOP $\left(a\right.$ and $\left.b_{b}\right)$ and $R_{r s}$ for 9 wavelengths, in 29 stations. Figure 4 shows that the QAA model is highly correlated with in-situ measurements measured in the same area as out study site $\left(\mathrm{R}^{2}=0.74\right)$.

[Insert Figure 4 about here]

\subsection{The methodological flowchart}

The image simulation process uses several numerical models, such as atmospheric, hydrodynamic, biogeochemical, hydro-sedimentary, water radiative transfer, atmosphere radiative transfer and sensor models. Figure 5 describes the simulator from the input parameters configuration to the simulated TOA radiance image as final output result. The first step of the simulation process is the seascape modelling. Once the study area and the period of measurement is determined, the coupled hydrodynamic-biogeochemical model (MAR3D-ECO3M, ME) and the coupled MARS3D-HydroSedimentary model (MS) are used to simulate the dynamics of chlorophyll concentration (chl), Particle Of Carbon (POC), and non-organic Suspended Particle Matter (SPM ${ }_{\text {norg }}$ ). These maps are then converted into IOPs maps used as input of water radiative transfer model to provide sea surface reflectance image, considering the wind speed $\left(W_{s p d}\right)$ and the geometrical maps $\left(\theta_{s}, \theta_{c}\right.$, and $\left.\Delta \phi\right)$. The atmospheric radiative transfer model simulates the absorption and the backscattering due to the atmosphere with the profile adapted to the local environment. At the end, the simulator provides the TOA radiance $L_{T O A}$ images containing the water and atmosphere information that would be provided by the sensor.

All models used are given in Table 3. All the intermediate data such as IOPs, water reflectance, atmospheric optical thickness, and atmospheric reflectance/transmittance are available so that the simulated images can be validated at the different levels: water surface or TOA levels.

[Insert Table 3 about here]

[Insert Figure 5 about here] 


\section{Results}

\subsection{Validation with MERIS}

To validate the image simulation, we firstly compared a simulated MERIS image to a real one. The MERIS image simulation is obtained by using MERIS level 2 products like $c h l, S P M$ and CDOM concentration maps as inputs of the simulator. The geometric angles and the wind speed maps provided by MERIS level 2 were also used. The simulated MERIS image can be compared with the acquired Level 1 MERIS image in order to validate the performance of the simulator. We then simulated the MERIS TOA radiance $\left(L_{T O A}\right)$ image on the Gulf of Lion on May $18^{\text {th }}$, 2008. The atmospheric parameters for this simulation are those described in part 2.4.

Figure 6.1 presents the TOA radiance (band 5, 560nm) of the real MERIS image that can be compared to the simulated TOA radiance for the same band. Visually, we can note similar plume on the Rhone River estuary in both simulated and acquired images, which demonstrates the consistency of the IOPs model and radiative transfer models. The simulated image is more homogeneous than the acquired image because of the assumption of the homogeneous atmospheric profile, but the method provides consistent visual results. On Figure 6.3, we can compare the TOA spectral radiance for 2 areas (one in the plume and one far from the coast). The difference between the simulated and real spectra is tiny. The radiance of the 2 areas are also similar. The 2 spectra differ only between 500 and $600 \mathrm{~nm}$. Once corrected from the atmospheric effect, we can also compare the remote sensing reflectance for the same 2 areas. The spectra from the 2 areas are now very different but the difference between the simulated and the real reflectance is very low.

[Insert Figure 6 about here]

Regarding quantitative aspects, Root Mean Square Error (RMSE), the relative error, the coefficient of determination $\mathrm{R}^{2}$ and the Mean Absolute Percentage Error (MAPE) are considered. Their definitions are given Table 4 .

[Insert Table 4 about here]

The RMSE and the relative error is given in Table 5 for 15 MERIS spectral bands. We found an average relative error at $4.76 \%$ for visible bands and at $16.51 \%$ for near infrared bands. The spectral correlation $\mathrm{R}^{2}$ was also calculated at different levels: top of atmosphere level ( $L_{T O A}$ images) and sea surface level ( $R_{r s}$ images). Between simulated and real $L_{T O A}$ images, the average $\mathrm{R}^{2}$ reaches 0.998 and between simulated and real $R_{r s}$ images, the average $\mathrm{R}^{2}$ reaches 0.972 .

[Insert Table 5 about here]

\subsection{Simulated GeoOCAPI images}

The ocean color images of the future GeoOCAPI sensor were simulated on the Gulf of Lion during the period between 13 and 23 May 2008. An example of these simulated images is presented on Figure 7.2. The real $L_{T O A}$ MERIS color composite image acquired at 10:00 on May 18, 2008 is presented on Figure 7.1.

On Figure 7.1 and Figure 7.2, we can notice the yellow plume of the Rhone River and the Cortiou outfall because of the high concentration of suspended matter in this area. 


\section{[Insert Figure 7 about here]}

Figure 7.3 plots the spectral radiance value given by MERIS in front of the Cortiou outfall $\left(43.33^{\circ} \mathrm{N}, 4.87^{\circ} \mathrm{E}\right)$. Figure 7.4 presents the simulated $L_{T O A}$ spectra of a pixel between 5:00 and 18:00 on the same location given by the GeoOCAPI image during the day. We can note the strong variability of the TOA radiance spectrum during the day. The variation of the $L_{T O A}$ here is in fact principally due to the solar angle variability between $24^{\circ}$ and $83^{\circ}$. We find the weakest signal at 5:00 and 18:00, when the solar zenithal angle is higher than $80^{\circ}$. The sensor zenithal angle $\theta_{c}$ is also different: $13^{\circ}$ for MERIS and $52^{\circ}$ for GeoOCAPI. The contribution of the atmosphere reflected radiance increases with $\theta_{c}$ especially at short wavelengths. This is the principal reason of the difference between the two spectra (at 10:00). For example, the difference of the atmosphere reflected radiance between $\theta_{c}=52^{\circ}$ and $\theta_{c}=$ $13^{\circ}$ is $11.5 \mathrm{~W} \cdot \mathrm{m}^{-2} \cdot \mathrm{sr}^{-1} \cdot \mu \mathrm{m}^{-1}$, at $412 \mathrm{~nm}$ with $\theta_{s}=25^{\circ}$, and this value decreases when the wavelength increases. To compare similar reflectance with the 2 sensors, the two images need to be corrected from the atmospheric effect.

Figure 8 presents the color composite of simulated GeoOCAPI TOA images on the Cortiou outfall during the $18^{\text {th }}$ May 2008 from 6:00 to 17:00. The MERIS image acquired on the same date at 10:00 is also presented. Its next revisit is May 21, 2008. We can notice that the MERIS sensor has a sufficient spatial resolution to detect the small plume due to outfall discharge but the evolution of the outfall discharge can only be tracked with the GEO images. On Figure 8 we can see that the urban outfall plume is diffused and pointing south in the morning while, the outfall plume becomes thinner and is pointing East in the afternoon. These images show the potential of a geostationary mission with hourly observation and $250 \mathrm{~m}$ nadir spatial resolution for the monitoring of the water quality variability due to an urban outfall discharge.

[Insert Figure 8 about here]

\subsection{Water composition estimation results}

The inversion method with QAA model was applied to the simulated images perfectly corrected from the atmospheric effect. This is possible because we simulated the atmospheric effect (all the atmospheric parameters are known) and we can then remove it perfectly. We can then compare only the sensor features influence on the estimation without the error due to the atmospheric correction. The retrieved water composition maps (chl, SPM and CDOM) are presented in Figure 9 (right) and can be compared to input maps (left).

[Insert Figure 9 about here]

Statistically, the MAPE is low for SPM (7.69\%) and CDOM (12.21\%) but high for chl estimation $(58.70 \%)$. The QAA model was initially used to retrieve the water depth and IOPs [42], [44] with good performance. On this site, the IOPs are dominated by suspended matter $(>1 \mathrm{~g} \cdot \mathrm{m}-3)$, and the absorption and scattering spectra is not sensitive to the presence of chlorophyll $(<1 \mathrm{mg} \cdot \mathrm{m}-3)$. This phenomenon is often met in coastal areas where the chlorophyll effect on the water colour is hidden by the strong backscattering of suspended matter [45].

The error can also be analyzed according to the geographic location. Figure 10 presents the temporal profile of $c h l, S P M$ and $C D O M$ in front of the Cortiou outfall $\left(5.39^{\circ} \mathrm{W}, 43.20^{\circ} \mathrm{N}\right)$ during the period from 13 to 23 May 2008. Black crosses correspond to ME and MS input models and grey squares correspond to estimations obtained from simulated GeoOCAPI images.

[Insert Figure 10 about here] 
The MAPE in this area is $47.68 \%$ for $c h l$ estimation, $16.45 \%$ for $S P M$ estimation and $8.72 \%$ for $C D O M$ estimation. If we choose an offshore area $\left(5.10^{\circ} \mathrm{W}, 43.12^{\circ} \mathrm{N}\right)$, far from the river and urban outfall plumes, the MAPE decreases especially for SPM values $(5.25 \%)$ but not for chl estimation $(53.07 \%)$ and CDOM estimation (17.41\%). With MERIS images, only 2 images would have been available during this period.

\section{Discussion}

For high dynamic coastal waters, an ocean color image simulator was developed to evaluate the potential of the GEO mission for the monitoring of the change water quality due to a river flow and an urban outfall. The originality of the method is the coupling of the hydrodynamics, bio-geochemical and radiative transfer derived from different digital models, which provides realistic images and validation data.

The comparison between the simulated MERIS image and the real image has shown a very close similarity. The RMSE is for all bands under $2.68 \mathrm{~W} \cdot \mathrm{m}^{-2} \cdot \mathrm{sr}^{-1} \cdot \mu \mathrm{m}^{-1}$ which is very weak for water color reflectance (Table 5). Even if the RMSE decreases with the wavelength, the relative error increases because the reflectance decreases also with the wavelength. For the first 9 bands (the most important for the water composition estimation), the relative error is under $10 \%$. This validation is important because it proves that we can trust the image simulation. The water dynamic reflectance provided by the simulator is spatially and temporally representative of the reality.

The simulator can also be used to test new algorithms adapted to geosynchronous sensors. In this study we tested the inversion method with QAA model to estimate the water composition. The QAA model can describe correctly the relationship between remote sensing reflectance and IOPs, consistent with in situ data and simulation and the inversion method works well for SPM and CDOM estimation. We showed that the estimation of SPM and CDOM was reliable in the river plume and outside where the water is less turbid. However, the estimation showed that $c h l$ was not accurately estimated neither in the river plume area nor off shore because wherever the sediment contribution is too high, $S P M$ is higher than $1 \mathrm{~g} \cdot \mathrm{m}^{-3}$, even in the offshore area. $R_{r s}$ spectrum is not sensitive to $c h l$ concentration which is in all areas lower than $1 \mathrm{mg} \cdot \mathrm{m}^{-3}$.

With our simulations, we can also compare the chl estimation with (SNR given in Table 1) and without the sensor noise. The error on chl estimation decreases from $53.07 \%$ (with the noise) to $24.30 \%$ (without the noise) in off shore area, and from $47.86 \%$ (without the noise) to $33.02 \%$ in front of the urban outfall. Because the estimations are more accurate without noise than with, it proves that the chlorophyll contribution in this area (the outfall plume) has little influence on the signal. This is particularly true when the $S P M$ concentration is high. Because the standard deviation increase with the square root of the signal, when the signal increases (due to the high SPM concentration), the noise increases with it and the chlorophyll influence on the signal is lost in the noise.

The problem of SNR ratio is often addressed in ocean color sciences. In Open Ocean, the water reflectance is often weak, the signal measured by the sensor is composed by around $90 \%$ by the atmosphere signal and around $10 \%$ by the water reflectance due to the only component (chlorophyll). The chlorophyll concentration can be at best estimated with an accuracy of around $30 \%$. In coastal areas, the signal due to the water reflectance is higher than in open waters but this is often due to the presence of suspended particulate matter. In that case, the SPM concentration can be accurately estimated which is no longer the case for the chlorophyll concentration. Our study shows here that how the SNR level is important even in coastal water. 
Concerning the Rhone River estuary and its high plume dynamics during the day, we showed the advantage of having 12 GeoOCAPI images per day, compared to only two with MERIS. The simulation of the GeoOCAPI shows that hourly images allows the more effective monitoring of the dynamics of the water quality in front of the Cortiou urban sewage outfall compared to MERIS. The high temporal resolution can also be used to early detect the pollution at the event beginning. The geostationary image can also be useful to monitor the pollution scattering especially concerning the direction of this pollution.

\section{Conclusion}

In this paper we presented a method to simulate geostationary images dedicated to water color monitoring. The originality of the method is based on the coupling of several models to simulate realistic geostationary images: biogeochemical and hydro-sedimentary models, the water radiative transfer model Hydrolight and atmosphere radiative transfer model MODTRAN. The sensor features are also taken into account with its spatial, spectral and temporal resolutions and SNR depending on the spectral bands. Real MERIS images were used to validate the simulator with an average relative error at $4.76 \%$ for visible bands and at $16.51 \%$ for near infrared bands. The GeoOCAPI simulated images were used to estimate the water composition with the QAA algorithm. The SPM and the CDOM were retrieved with considerable accuracy, the error is respectively $7.69 \%$ and $12.21 \%$. The chl is misestimated $(58.10 \%)$ due to the low concentration in this area $(<1 \mathrm{mg} \cdot \mathrm{m}-3)$ compared to $S P M(>1$ $\mathrm{g} \cdot \mathrm{m}-3)$. We then showed the performances of GeoOCAPI images to estimate water composition and the advantages to dispose of geostationary images to detect and monitor the Rhone River estuary and the urban outfall of Cortiou in the Gulf of Lion.

\section{Acknowledgment}

This research was supported by the CNES (Centre National d'Etudes Spatiales, France) TOSCA funding. The authors are grateful to the European Space Agency for providing the MERIS data and to the CNES for the Kalicôtier site. We also thank the Laboratory of Villefranche/mer for providing some data from Optic-Med program and ACRI-ST for the MM5 meteorological outputs. 


\section{References}

[1] IOCCG, "Ocean-Colour Observations from a Geostationary Orbit," Dartmouth, Canada, 12, 2012.

[2] G. Neukermans, K. Ruddick, E. Bernard, D. Ramon, B. Nechad, and P. Y. Deschamps, "Mapping total suspended matter from geostationary satellites: a easiblility study with SEVIRI in the Southern Norht Sea," Opt. Express, vol. 17, pp. 14029-14052, Aug. 2009.

[3] G. Neukermans, K. Ruddick, and N. Greenwood, "Diurnal variability of turbidity and light attenuation in the southern North Sea from the SEVIRI geostationary sensor," Remote Sens. Environ., vol. 124, pp. 564-580, 2012.

[4] J.-H. Ryu, H.-J. Han, S. Cho, Y.-J. Park, and Y.-H. Ahn, "Overview of geostationary ocean color imager (GOCI) and GOCI data processing system (GDPS)," Ocean Sci. J., vol. 47, no. 3, pp. 223-233, 2012.

[5] J.-K. Choi, Y.-J. Park, B. R. Lee, J. Eom, J.-E. Moon, and J.-H. Ryu, "Application of the Geostationary Ocean Color Imager (GOCI) to mapping the temporal dynamics of coastal water turbidity," Remote Sens. Environ., vol. 146, no. 0, pp. 24 - 35, 2014.

[6] D. Doxaran, N. Lamquin, Y.-J. Park, C. Mazeran, J.-H. Ryu, M. Wang, and A. Poteau, "Retrieval of the seawater reflectance for suspended solids monitoring in the East China Sea using MODIS, MERIS and GOCI satellite data," Remote Sens. Environ., vol. 146, no. 0, pp. 36 - 48, 2014.

[7] X. He, Y. Bai, D. Pan, N. Huang, X. Dong, J. Chen, C. T. A. Chen, and Q. Cui, "Using geostationary satellite ocean color data to map the diurnal dynamics of suspended particulate matter in coastal waters," Remote Sens. Environ., vol. 133, pp. 225-239, 2013.

[8] X. Lou and C. Hu, "Diurnal changes of a harmful algal bloom in the East China Sea: Observations from GOCI," Remote Sens. Environ., vol. 140, no. 0, pp. 562 - 572, 2014.

[9] M. Wang, J.-H. Ahn, L. Jiang, W. Shi, S.-H. Son, Y.-J. Park, and J.-H. Ryu, “Ocean color products from the Korean Geostationary Ocean Color Imager (GOCI)," Opt. Express, vol. 21, no. 3, pp. 3835-3849, Feb. 2013.

[10] D. Antoine, "Ocean Colour Advanced Permanent Imager: OCAPI. Mission requirement Document (MRD, v1.0)." Antoine, D., 21-Jun-2010.

[11] H. Bach and W. Mauser, "Extraction of agricultural parameters from imaging-spectrometry data and simulated MERIS data through red edge analysis," in EISAC'89, Proceedings of an ESA and JRC-IRSA Workshop, 1989, pp. 81-91.

[12] J. H. Everitt, J. R. Escobar, J. R. Noriega, I. Cavazos, and M. R. Davis, “A video system capable of simulating landsat TM imagery,” Remote Sens. Environ., vol. 62, pp. 40-45, 1997.

[13] S. Jeong, Y. Jeong, D. Ryu, S. Kim, S. Cho, J. Hong, S. W. Kim, and H. S. Youn, "In-orbit imaging and radiometric performance prediction for flight model geostationary ocean color imager," in SPIC Proc., 2009.

[14] W. Verhoef and H. Bach, "Simulation of hyperspectral and directional radiance images using coupled biophysical and atmospheric radiative transfer models," Remote Sens. Environ., vol. 87, pp. 23-41, 2003.

[15] W. Verhoef and H. Bach, "Simulation of Sentinel-3 images by four-stream surface-atmosphere radiative transfer modeling in the optical and thermal domains," Remote Sens. Environ., vol. 120, no. 0, pp. $197-207,2012$.

[16] M. Lei, A. Minghelli-Roman, A. Bricaud, J.-M. Froidefond, S. Mathieu, and P. Gouton, "Simulation of Future Geostationary Ocean Color Images," IEEE J. Sel. Top. Appl. Earth Obs. Remote Sens., vol. 5, no. 1, pp. 173-182, 2012.

[17] P. Lazure and F. Dumas, "An external-internal mode coupling for a 3D hydrodynamical model for applications at regional scale (MARS)," Adv. Water Resour., vol. 31, no. 2, pp. 233 - 250, 2008. 
[18] A. Nicolle, P. Garreau, and B. Liorzou, "Modelling for anchovy recruitment studies in the Gulf of Lions (Western Mediterranean Sea)," Ocean Dyn., vol. 59, no. 6, pp. 953-968, 2009.

[19] I. Pairaud, J. Gatti, N. Bensoussan, R. Verney, and P. Garreau, "Hydrology and circulation in a coastal area off Marseille: Validation of a nested 3D model with observations," J. Mar. Syst., vol. 88, no. 1, pp. 20-33, 2011.

[20] R. Verney, C. Jany, B. Thouvenin, I. Pairaud, M. Vousdoukas, C. Pinazo, F. Ardhuin, and P. Cann, "Sediment Transport in the Bay of Marseille: Role of Extreme Events," in Coastal Dynamics, Arcachon, France, 2013.

[21] M. Fraysse, Christel P., V. M. Faure, R. Fuchs, P. Lazzari, P. Raimbault, and I. Pairaud, "Development of a 3D Coupled Physical-Biogeochemical Model for the Marseille Coastal Area (NW Mediterranean Sea): What Complexity Is Required in the Coastal Zone?," PLoS ONE, vol. 8, no. 12, p. e80012, 2013.

[22] M. Baklouti, F. Diaz, C. Pinazo, V. Faure, and B. Quéguiner, "Investigation of mechanistic formulations depicting phytoplankton dynamics for models of marine pelagic ecosystems and description of a new model," Prog. Oceanogr., vol. 71, pp. 1-33, 2006.

[23] M. Baklouti, V. Faure, L. Pawlowski, and A. Sciandra, "Investigation and sensitivity analysis of a mechanistic phytoplankton model implemented in a new modular numerical tool (Eco3M) dedicated to biogeochemical modelling," Prog. Oceanogr., vol. 71, no. 1, pp. 34-58, 2006.

[24] M. Fraysse, I. Pairaud, O. N. Ross, V. M. Faure, and C. Pinazo, "Intrusion of Rhone River diluted water into the Bay of Marseille: Generation processes and impacts on ecosystem functioning," $J$. Geophys. Res. Oceans, vol. 119, no. 10, pp. 6535-6556, 2014.

[25] N. A. Phillips, "A coordinate system having some special advantages for numerical forecasting," J. Meteorol., vol. 14, no. 2, pp. 184-185, 1957.

[26] H. R. Gordon and D. K. Clark, "Remote sensing optical properties of a stratified ocean: an improved interpretation," Appl. Opt., vol. 19, pp. 3248-3430, 1980.

[27] J. R. Zaneveld, A. Barnard, and E. Boss, "Theoretical derivation of the depth average of remotely sensed optical parameters," Opt. Express, vol. 13, pp. 9052-9061, 2005.

[28] M. Babin, A. Morel, V. Fournier-Sicre, F. Fell, and D. Stramski, "Light scattering properties of marine particles in coastal and oceanic waters as related to the particle mass concentration," Limnol. Oceanogr., vol. 48, pp. 843-859, 2003.

[29] M. Babin, D. Stramski, G. M. Ferrari, H. Claustre, A. Bricaud, G. Obolensky, and N. Hoepffner, "Variations in the light absorption coefficients of phytoplankton, nonalgal particles, and dissolved organic matter in coastal waters around Europe," J. Geophys. Res., vol. 108, p. 3211, 2003.

[30] R. M. Pope and E. S. Fry, “Absorption spectrum (380-700 nm) of pure water. II. Integrating cavity measurements," Appl. Opt., vol. 36, pp. 8710-8723, 1997.

[31] D. Segelstein, "The complex refractive index of water," M.S.Thesis, University of Missouri, Kansas City, 1981.

[32] R. C. Smith and K. S. Baker, "Optical properties of the clearest natural waters (200-800 nm)," Appl. Opt., vol. 20, pp. 177-184, 1981.

[33] A. Morel, "Optical properties of pure water and pure sea water," in Optical Aspects of Oceanography, New York: Academic Press, 1974.

[34] C. D. Mobley, Light and Water: Radiative Transfer in Natural Waters. Academic, 1994.

[35] T. J. Petzold, "Volume scattering functions for selected ocean waters," Scripps Institution of Oceanography, UC San Diego, SIO-REF-72-78, 1972.

[36] A. Bricaud, A. Morel, M. Babin, K. Allali, and H. Claustre, "Variation of light absoption by suspended particles with chlorophyll a concentration in oceanic (case 1) waters: analysis and implications for bio-optical models," J. Geophys. Res., vol. 103, pp. 31033-31044, 1998. 
[37] A. Bricaud, M. Aguirre, A. Morel, and H. Claustre, "Variability in the chlorophyll-specific absorption coefficients of natural phytoplankton: Analysis and parameterization," J. Geophys. Res., vol. 100, pp. 13321-13332, 1995.

[38] C. D. Mobley and L. K. Sundman, "Hydrolight 5, Ecolight 5 User Guide," Sequoia Scientific, Inc., 2008.

[39] E. F. Vermote, D. Tanre, J. L. Deuze, M. Herman, and J. J. Morcrette, "Second Simulation of the Satellite Signal in the Solar Spectrum, 6S: An Overview," IEEE Trans. Geosci. Remote Sens., vol. 35, pp. 675-686, 1997.

[40] A. Berk, G. P. Anderson, P. K. Acharya, J. H. Chetwynd, L. S. Bernstein, E. P. Shettle, M. W. Matthew, and S. M. Adler-Golden, "MODTRAN4 USER'S MANUAL." Jun-1999.

[41] Z. Lee, K. L. Carder, C. D. Mobley, R. G. Steward, and J. S. Patch, "Hyperspectral Remote Sensing for Shallow Waters. I. A Semianalytical Model,” Appl. Opt., vol. 37, no. 27, pp. 63296338, 1998.

[42] Z. Lee, K. L. Carder, and R. A. Arnone, "Deriving Inherent Optical Properties from Water Color: a Multiband Quasi-Analytical Algorithm for Optically Deep Waters," Appl. Opt., vol. 41, no. 27, pp. 5755-5772, 2002.

[43] T. Lorthiois, "Dynamique des matières en suspension dans le panache du Rhône (Méditeranée occidentale) par télédétection spatiale," Université Pierre et Marie Curie, 2012.

[44] Z. Lee, K. L. Carder, C. D. Mobley, R. G. Steward, and J. S. Patch, "Hyperspectral Remote Sensing for Shallow Waters. 2. Deriving Bottom Depths and Water Properties by Optimization," Appl. Opt., vol. 38, no. 18, pp. 3831-3843, 1999.

[45] F. Gohin, J. N. Druon, and L. Lampert, "A five channel chlorophyll concentration algorithm applied to SeaWiFS data processed by SeaDAS in coastal waters," Int. J. Remote Sens., vol. 23, pp. 1639-1661, 2002. 


\begin{tabular}{|c|c|c|c|c|c|c|c|c|}
\hline \multirow{2}{*}{ Band } & \multirow{2}{*}{$\begin{array}{c}\lambda \\
(\mathbf{n m})\end{array}$} & \multirow{2}{*}{$\begin{array}{c}\Delta \lambda \\
(\mathbf{n m})\end{array}$} & $\mathbf{L}_{\min }$ & $\mathbf{L}_{\text {ref }}$ & $\mathbf{L}_{\max }$ & $\begin{array}{c}\mathbf{L}_{\text {max, }}, \\
\text { ocean }\end{array}$ & \multirow{2}{*}{$\begin{array}{l}\text { SNR@ } \\
250 \mathrm{~m}^{1} \\
\text { and } \mathrm{L}_{\text {ref }}\end{array}$} & \multirow{2}{*}{ Use } \\
\hline & & & \multicolumn{4}{|c|}{$\mathrm{W} \mathrm{\textrm {m } ^ { - 2 }} \mathrm{sr}^{-1} \mu \mathrm{m}^{-1}$} & & \\
\hline 1 & 395 & 10 & 12 & 65 & 580 & 180 & 400 & $c h l-C D O M$ separation \\
\hline 2 & 412 & 20 & 12 & 70 & 550 & 190 & 400 & $\begin{array}{l}C D O M, \text { possibly } \\
\text { atmospheric correction } \\
\text { above "black waters" }\end{array}$ \\
\hline 3 & 442 & 20 & 12 & 65 & 650 & 185 & 400 & chl, SPM, CDOM \\
\hline 4 & 470 & 20 & 11 & 60 & 650 & 175 & 400 & $\begin{array}{l}\text { Specific anomalies of the } \\
\text { reflectance spectrum }\end{array}$ \\
\hline 5 & 490 & 20 & 10 & 50 & 665 & 165 & 400 & $\begin{array}{l}\text { chl, SPM, CDOM, } \\
\text { Diffuse attenuation } \\
\text { coefficient, Secchi } \\
\text { transparency }\end{array}$ \\
\hline 6 & 510 & 20 & 8 & 45 & 620 & 155 & 400 & $\begin{array}{l}\text { chl, SPM, CDOM, } \\
\text { detection of blue- } \\
\text { absorbing dust-like } \\
\text { aerosols }\end{array}$ \\
\hline 7 & 560 & 20 & 6 & 30 & 580 & 132 & 300 & $\begin{array}{l}\text { chl, SPM, turbidity } \\
\text { index, Secchi } \\
\text { transparency }\end{array}$ \\
\hline 8 & 590 & 20 & 5 & 25 & 550 & 120 & 300 & $\begin{array}{l}\text { Spectral slope } b_{b p}, \max \\
R \text { in Case } 2 \text { waters }\end{array}$ \\
\hline 9 & 620 & 20 & 4 & 20 & 550 & 95 & 300 & $c h l, S P M$ \\
\hline 10 & 660 & 20 & 3 & 15 & 500 & 86 & 300 & $\begin{array}{l}\text { chl }, S P M, \text { chl } \\
\text { fluorescence (baseline) }\end{array}$ \\
\hline 11 & 681 & 7.5 & 3 & 15 & 500 & 82 & 200 & chl fluorescence (peak) \\
\hline 12 & 709 & 10 & 3 & 13 & 450 & 75 & 200 & $\begin{array}{l}\text { chl, SPM, Secchi } \\
\text { transparency, chl } \\
\text { fluorescence (baseline) }\end{array}$ \\
\hline 13 & 750 & 15 & 3 & 11 & 450 & 65 & 150 & Atmospheric corrections \\
\hline 14 & 754 & 7.5 & 2 & 10 & 400 & 65 & 150 & Reference for $\mathrm{O} 2 \mathrm{~A}-\mathrm{band}$ \\
\hline 15 & 761 & 2.5 & 2 & 6 & 400 & 63 & 30 & $\begin{array}{l}\text { O2 A-Band (aerosol } \\
\text { scale height, clouds) }\end{array}$ \\
\hline 16 & 779 & 15 & 2 & 9 & 380 & 60 & 150 & Atmospheric corrections \\
\hline 17 & 865 & 35 & 1 & 6 & 300 & 45 & 150 & Atmospheric corrections \\
\hline 18 & 1020 & 40 & 1 & 4 & 220 & 45 & 150 & $\begin{array}{l}\text { Atmospheric corrections } \\
\text { (turbid waters), cirrus } \\
\text { clouds }\end{array}$ \\
\hline
\end{tabular}

Table 1. OCAPI band set, including radiometric information and band use. $\mathrm{L}_{\min }$ are minimum radiance values that should be measured over the ocean, $\mathrm{L}_{\text {ref }}$ are typical ocean radiances, $\mathrm{L}_{\max }$ are maximum radiances that correspond to non-ocean bright targets (clouds), and $\mathrm{L}_{\text {max,ocean }}$ is the maximum radiance that should be measured above the ocean.

\footnotetext{
${ }^{1}$ These values lead to $\mathrm{SNR}>1500$ in the visible for a $1-\mathrm{km}$ resolution (i.e., $4 \mathrm{X} 4250 \mathrm{~m}$ pixels)
} 


\begin{tabular}{|c|c|c|c|c|c|c|}
\hline & $\theta_{c}$ & $\Delta \phi$ & $\theta_{s}$ & $W_{s p d}$ & $a_{n w}$ & $b_{p}$ \\
\hline$R_{r s}$ & + & + & + & + & + & + \\
\hline$R_{r e f l}$ & + & + & + & + & & \\
\hline$\rho_{a t m}$ & + & + & + & & & \\
\hline$S$ & + & + & + & & & \\
\hline$T_{s}$ & + & + & + & & & \\
\hline$T_{\text {dir }}$ & + & + & + & & & \\
\hline$T_{\text {dif }}$ & + & + & + & & & \\
\hline
\end{tabular}

Table 2. List of generated LUTs and their input parameters dependency 


\begin{tabular}{|c|c|c|c|}
\hline Model name & Function & Inputs & Outputs \\
\hline MM5 & $\begin{array}{l}\text { Meteorological } \\
\text { modelling }\end{array}$ & $\begin{array}{l}\text { OBC forced by } \\
\text { ECMWF }\end{array}$ & $\begin{array}{l}\text { Wind, air temperature, } \\
\text { atmospheric fluxes } \\
\text { Temperature, } \\
\text { pressure, humidity and } \\
\text { aerosol }\end{array}$ \\
\hline WW3 & Sea state modelling & wind from ECMWF & Wave, orbital velocity \\
\hline ME & $\begin{array}{l}\text { Coupled } \\
\text { biogeochimical } \\
\text { modelling }\end{array}$ & $\begin{array}{l}\text { River contributions, } \\
\text { WWTP contributions, } \\
\text { Atmospheric } \\
\text { contributions, } \\
\text { Hydrodynamic and } \\
\text { biogeochimical OBC } \\
\text { at the south and west } \\
\text { border from MENOR } \\
\text { and goL models }\end{array}$ & chl and $P O C$ 3D map \\
\hline MS & $\begin{array}{l}\text { Sedimentary transport } \\
\text { modelling }\end{array}$ & $\begin{array}{l}\text { Meteorological } \\
\text { forcing } \\
\text { River contributions, } \\
\text { WWTP contributions, } \\
\text { Hydrodynamics OBC } \\
\text { at the south and west } \\
\text { border from MENOR } \\
\text { model } \\
\text { Wave shear stress } \\
\text { from WW3 orbital } \\
\text { velocity }\end{array}$ & $S P M_{\text {norg }}$ 3D map \\
\hline Hydrolight & $\begin{array}{l}\text { Water radiative } \\
\text { transfer modelling }\end{array}$ & $\begin{array}{l}\text { Atmospheric profile, } \\
\text { Sun and sensor angles, } \\
\text { IOPs, } \\
\text { Wind speed }\end{array}$ & $\begin{array}{l}\text { Sea Surface } \\
\text { reflectance } R_{r s}(\lambda)\end{array}$ \\
\hline MODTRAN & $\begin{array}{l}\text { Atmosphere radiative } \\
\text { transfer modelling }\end{array}$ & $\begin{array}{l}\text { Atmospheric profile, } \\
\text { Sun and sensor angles }\end{array}$ & $\begin{array}{l}\text { Atmospheric } \\
\text { reflectance }\left(\rho_{a t m}\right) \text { and } \\
\text { transmittances }\left(T_{s}, T_{d i r}\right. \\
\left.\text { and } T_{d i r}\right) \text {, the } \\
\text { extraterrestrial solar } \\
\text { irradiance }\left(E_{S}\right) \text {, } \\
\text { atmosphere spherical } \\
\text { reflectance }(S)\end{array}$ \\
\hline
\end{tabular}

Table 3. Models used for the simulation.

OBC: Open Boundary Conditions

ECMWF: European Centre for Medium-Range Weather Forecasts

WWTP: Waste water Treatment Plant (Cortiou) 


\begin{tabular}{|c|c|}
\hline Parameter & Definition \\
\hline $\begin{array}{c}\text { The Root mean square error (RMSE) } \\
\text { Ideal }=0\end{array}$ & $R M S E=\sqrt{\frac{1}{n} \sum_{i=1}^{n}\left(x_{i}-y_{i}\right)^{2}}$ \\
\hline $\begin{array}{c}\text { The relative error (RE) } \\
\text { Ideal }=0\end{array}$ & $R D=\frac{|x-y|}{x}$ \\
\hline The coefficient of determination (R $\left.{ }^{2}\right)$ & $R^{2}=\frac{[\operatorname{cov}(x ; y)]^{2}}{\sigma^{2}(x) \sigma^{2}(y)}$ \\
\hline Ideal $=1$ & $M A P E=\frac{1}{n} \sum_{i=1}^{n} \frac{\left|x_{i}-y_{i}\right|}{x_{i}}$ \\
\hline Ideal $=0$
\end{tabular}

Table 4. Definition of validation parameters (RMSE, RE, $\mathrm{R}^{2}$ and MAPE) 


\begin{tabular}{|c|c|c|}
\hline $\boldsymbol{\lambda}$ & $\mathbf{R M S E}$ & Relative Error \\
\hline $\mathbf{( n m})$ & $\left(\mathbf{W} / \mathbf{m}^{2} / \mathbf{s r} / \boldsymbol{\mu m}\right)$ & $\mathbf{( \% )}$ \\
\hline $\mathbf{4 1 2}$ & 2.68 & $3.43 \%$ \\
\hline $\mathbf{4 4 2}$ & 1.83 & $2.44 \%$ \\
\hline $\mathbf{4 9 0}$ & 1.11 & $1.72 \%$ \\
\hline $\mathbf{5 1 0}$ & 1.02 & $1.89 \%$ \\
\hline $\mathbf{5 6 0}$ & 1.07 & $3.03 \%$ \\
\hline $\mathbf{6 2 0}$ & 1.12 & $5.04 \%$ \\
\hline $\mathbf{6 6 5}$ & 1.35 & $7.25 \%$ \\
\hline $\mathbf{6 8 1}$ & 1.43 & $8.22 \%$ \\
\hline $\mathbf{7 0 9}$ & 1.47 & $9.81 \%$ \\
\hline $\mathbf{7 5 4}$ & 1.58 & $12.83 \%$ \\
\hline $\mathbf{7 6 1}$ & 0.37 & $7.34 \%$ \\
\hline $\mathbf{7 7 9}$ & 1.48 & $13.55 \%$ \\
\hline $\mathbf{8 6 5}$ & 1.81 & $24.28 \%$ \\
\hline $\mathbf{8 8 5}$ & 1.83 & $26.55 \%$ \\
\hline $\mathbf{9 0 0}$ & 0.75 & $14.51 \%$ \\
\hline
\end{tabular}

Table 5. Root Mean Square Error and relative error between simulated TOA radiance $L_{T O A}$ images and measured MERIS images, in $\mathrm{W} \cdot \mathrm{m}^{-2} \cdot \mathrm{sr}^{-1} \cdot \mu \mathrm{m}^{-1}$. 


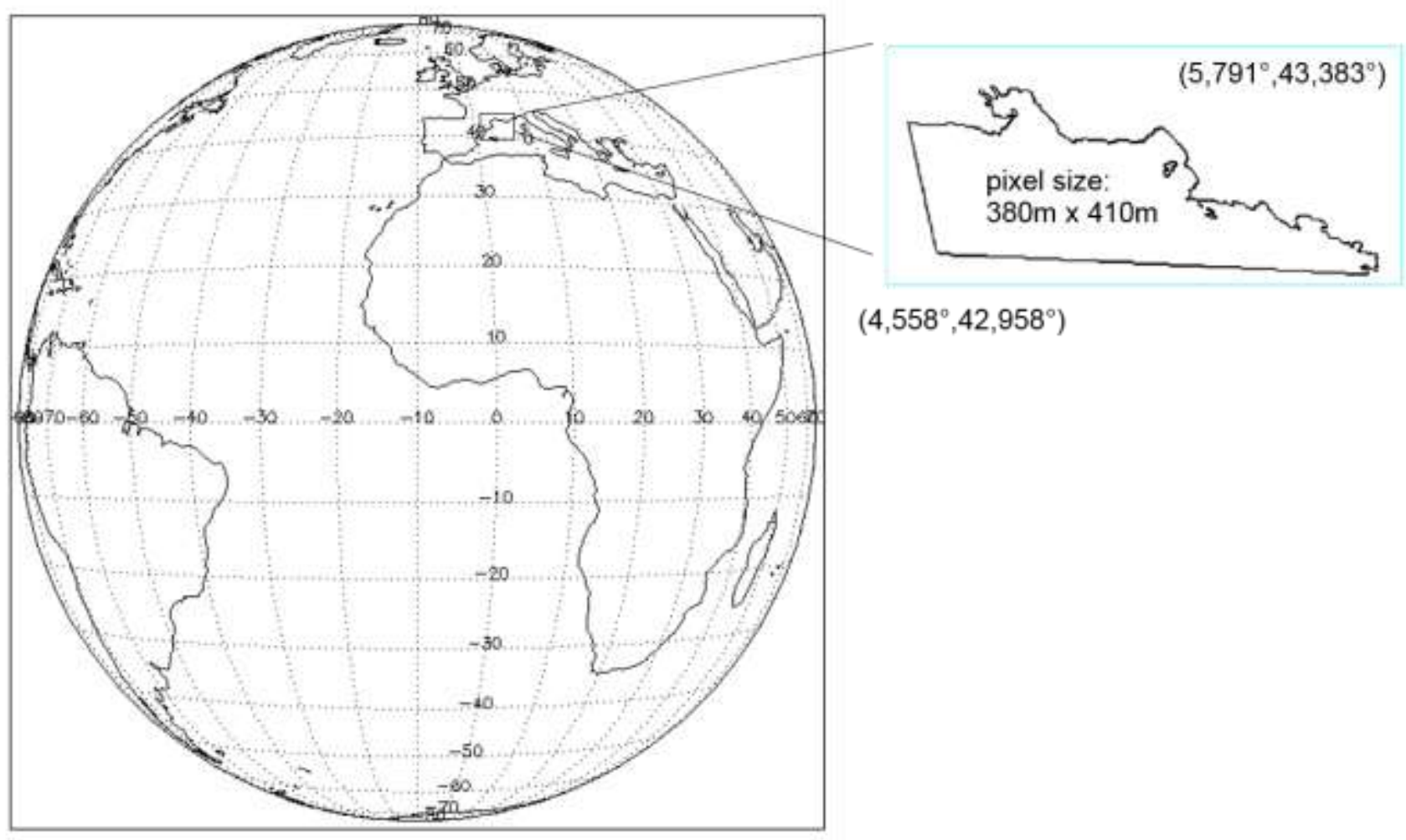

Figure 1. Geographic location of the study site (Gulf of Lion) as will be viewed by the GeoOCAPI sensor. 

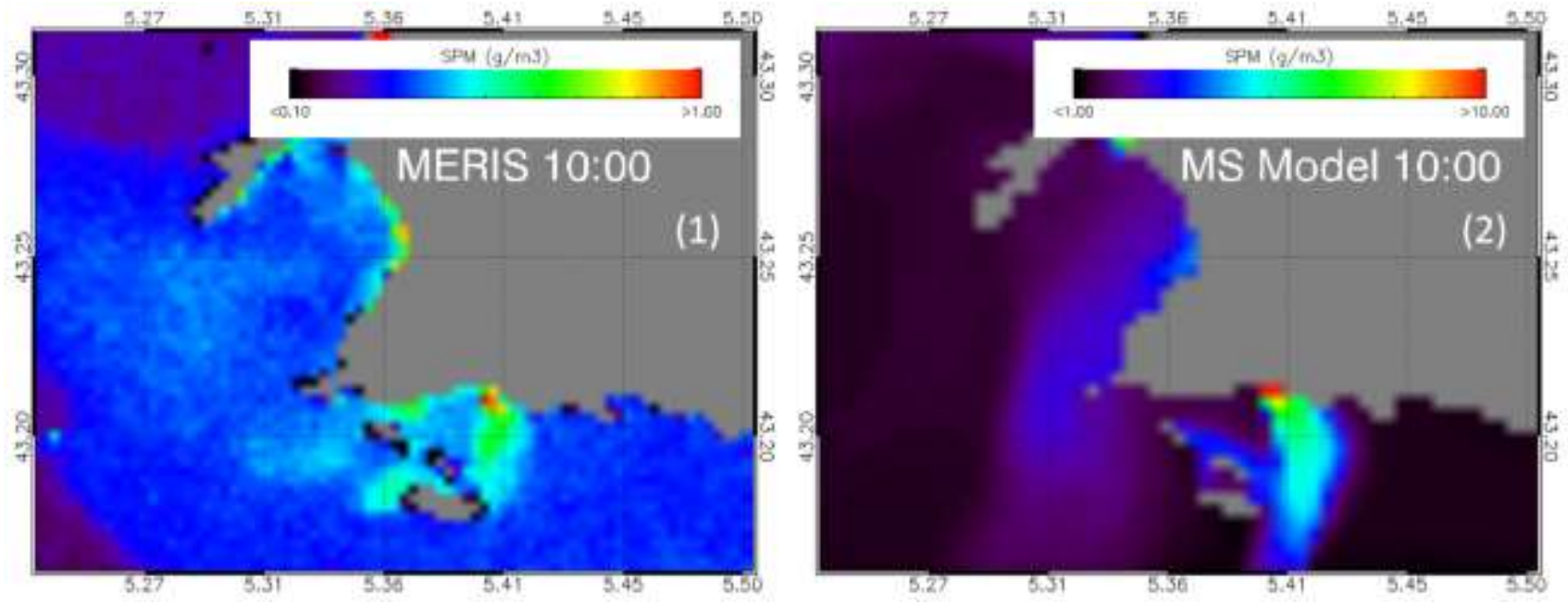

Figure 2. (1) MERIS SPM concentration map $\left(\mathrm{g} \cdot \mathrm{m}^{-3}\right)$ at 10:00 on May 18, 2008, (2) simulated $S P M_{\text {norg }}$ map at the same time. The discharge of the Cortiou outfall can be seen on the 2 maps. 


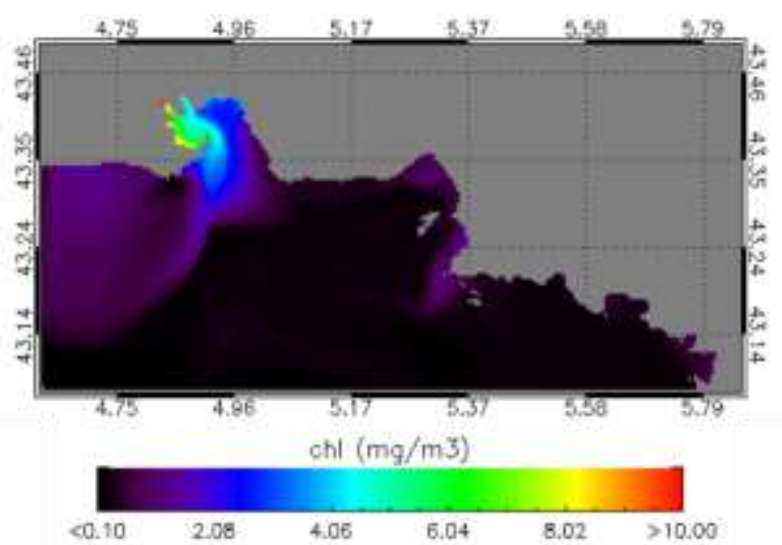

(1)

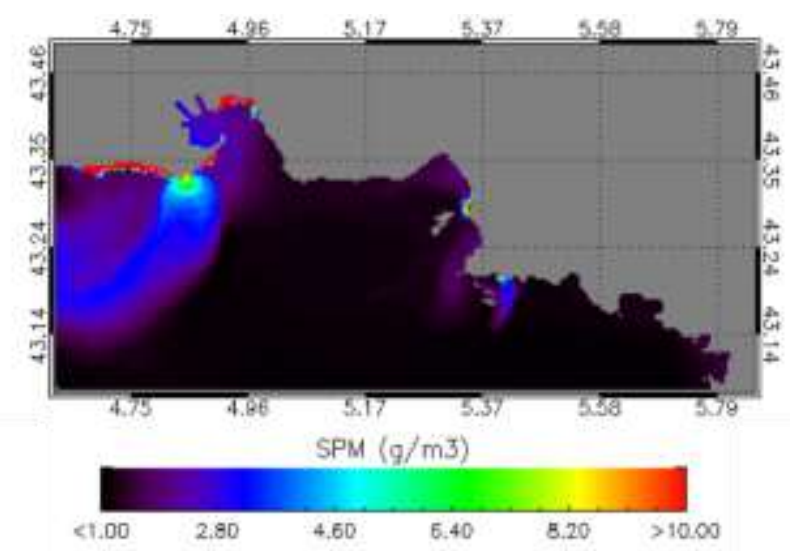

(2)

Figure 3. chl (1) and SPM (2) maps provided by ME model and MS model in the eastern Gulf on Lion on 18 May 2008, 10:00. 


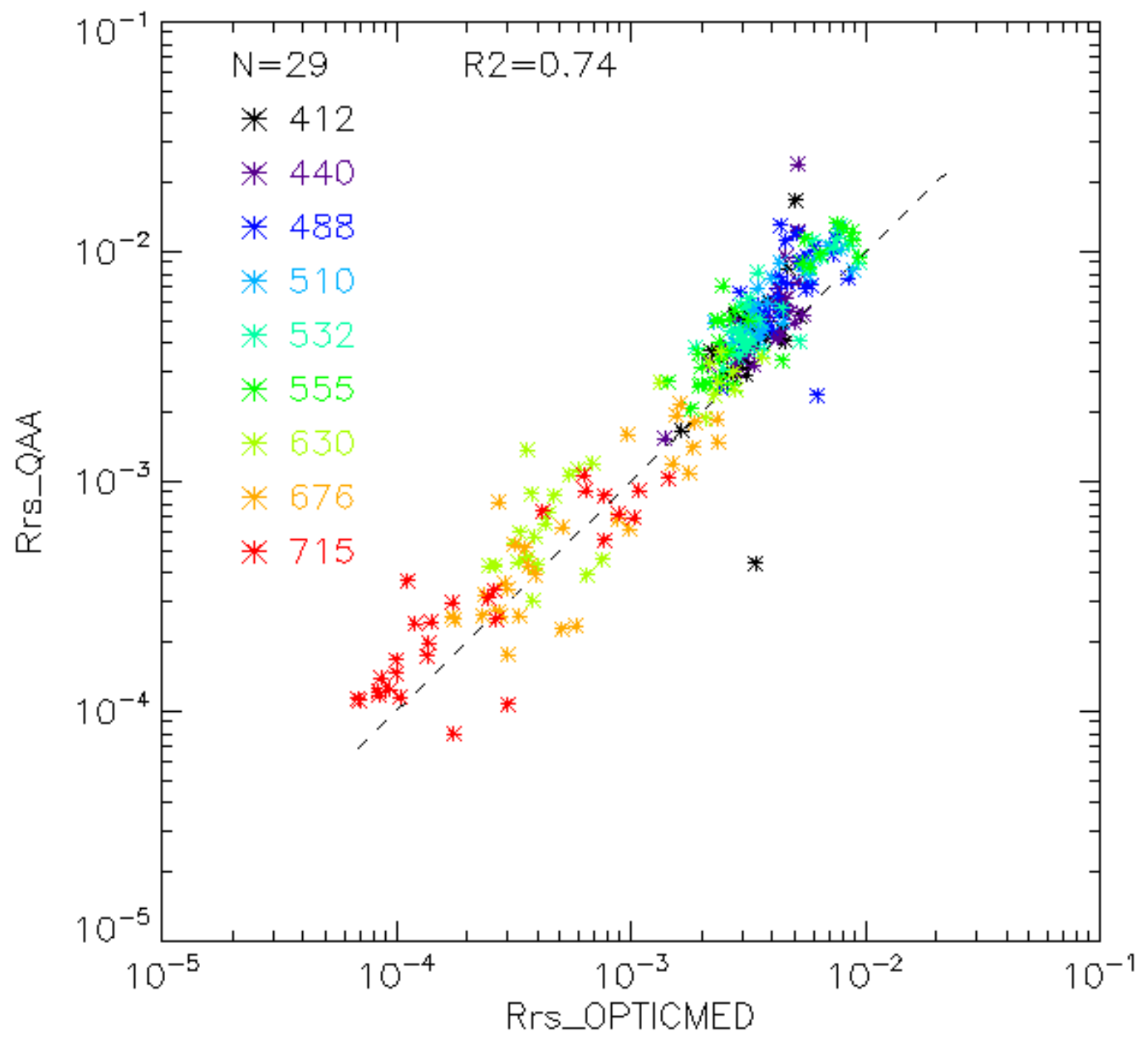

Figure 4. Comparison between QAA $R_{r s}$ and the in-situ Optic-Med measured $R_{r s}$. In-situ data contain the measured IOPs and $R_{r s}$ from 29 stations at 9 wavelengths. 


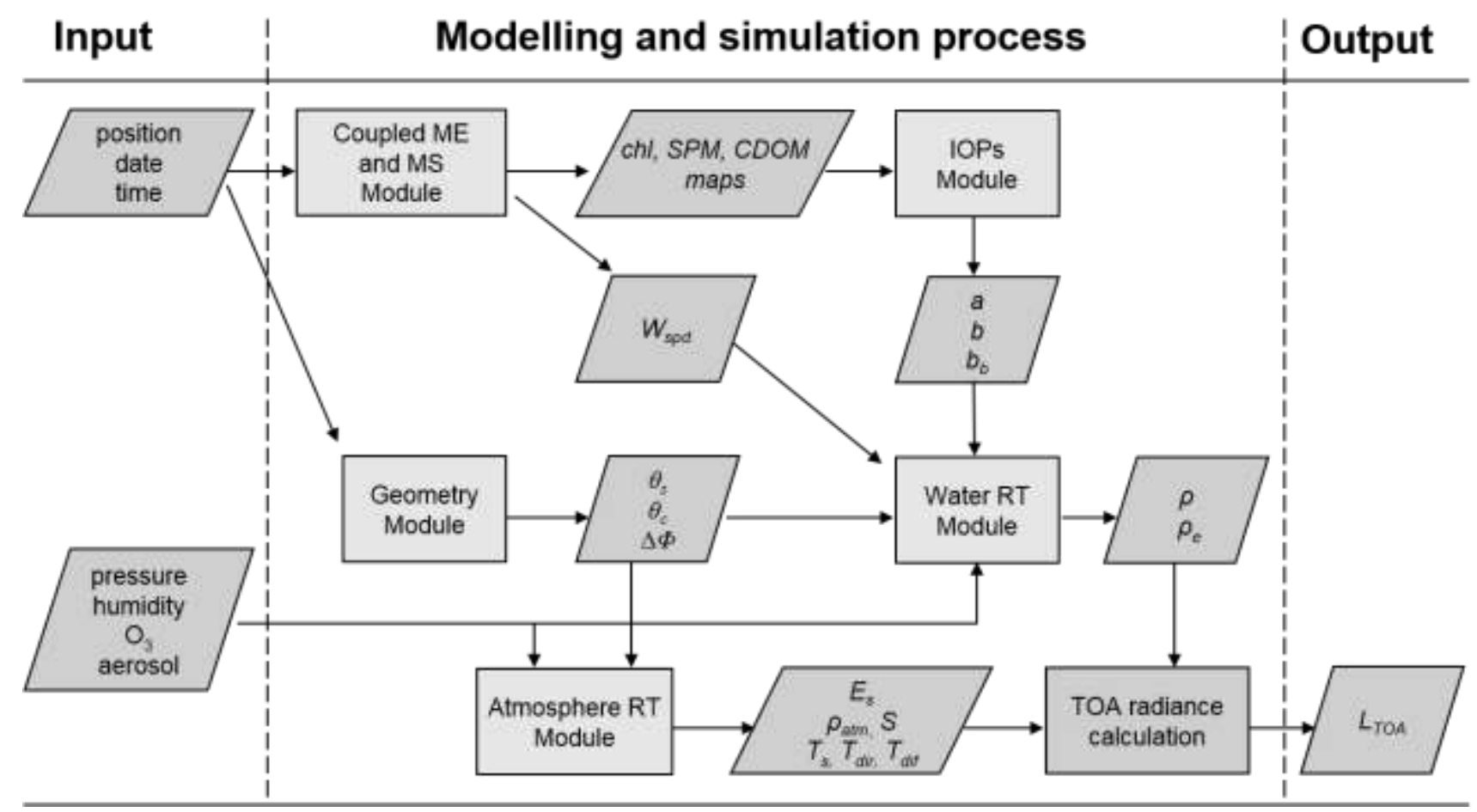

Figure 5. Modelling and simulation flowchart. 

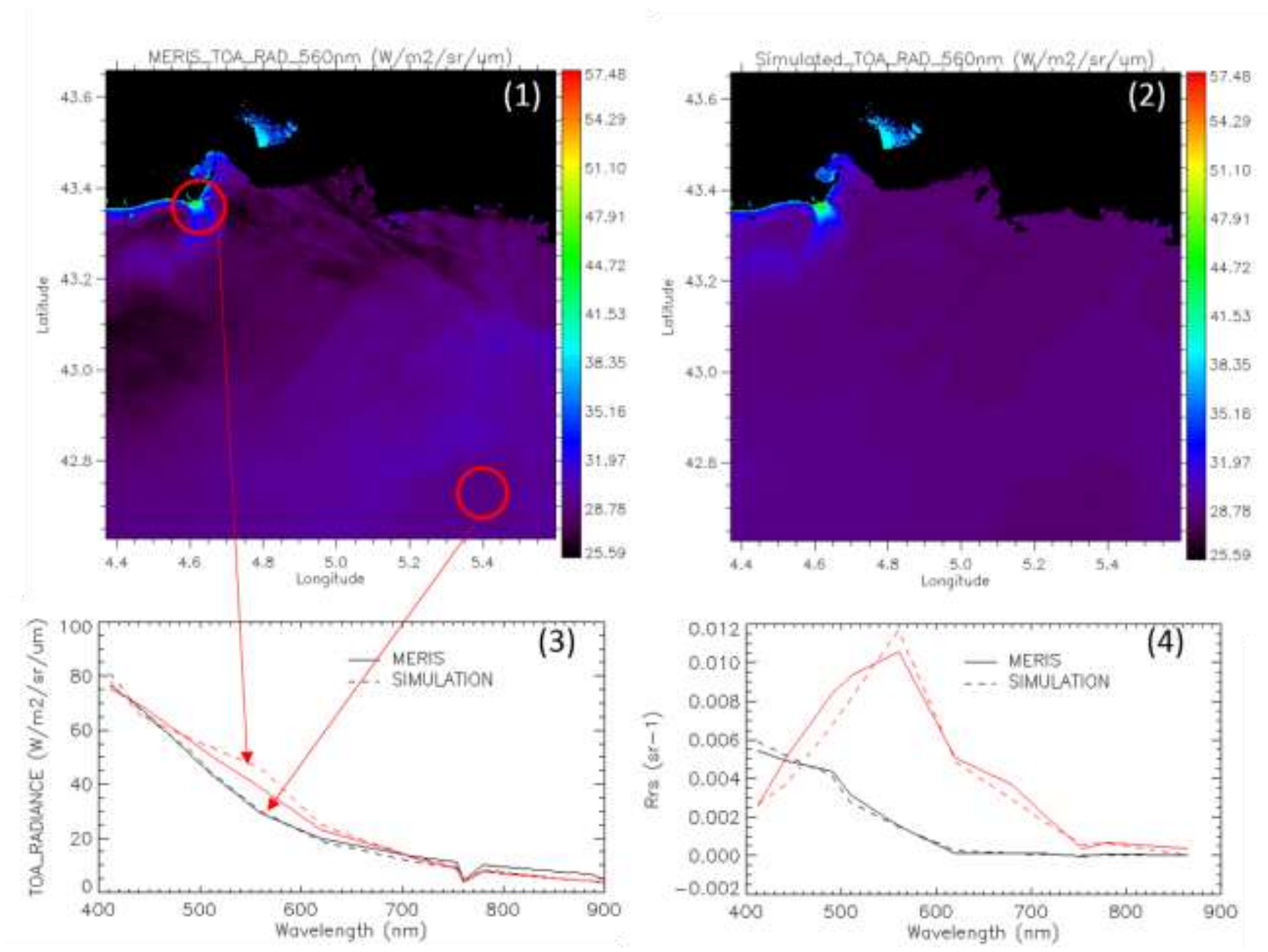

Figure 6. Comparison of real MERIS TOA radiance image for channel $5(560 \mathrm{~nm})$ with the simulated TOA radiance image using MERIS level2 products (component maps, sun and sensor angles, $W_{s p d}$ ) as inputs of the simulator on the Gulf of Lion on the 18 may 2008, 10:00. (1) MERIS image, (2) Simulated image, (3) TOA radiance spectrum, (4) $R_{r s}$ spectrum. 

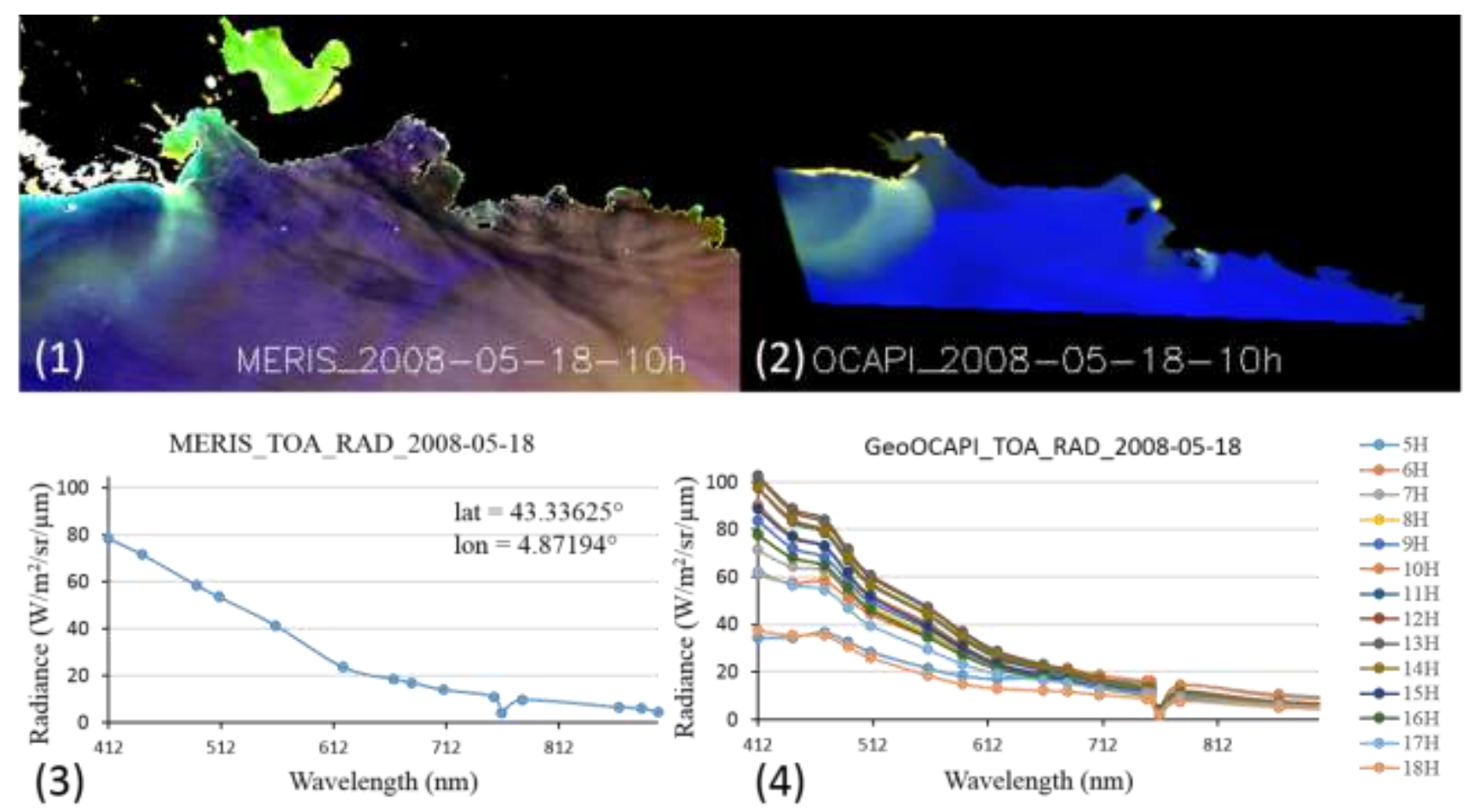

Figure 7. GeoOCAPI image simulation result at 18 May 2008, 10h00. The water composition maps is presented in Figure 33. (1) Measured MERIS TOA radiance color composite, red $=681 \mathrm{~nm}$, green $=$ $560 \mathrm{~nm}$, blue $=442 \mathrm{~nm}$, (2) Simulated GeoOCAPI TOA radiance color composite, same color composition, (3) TOA radiance spectra measured by MERIS at 10:00 in front of Cortiou outfall $\left(43.33^{\circ} \mathrm{N}, 4.87^{\circ} \mathrm{E}\right)$, (4) Simulated TOA corresponding radiance spectra during the day. 


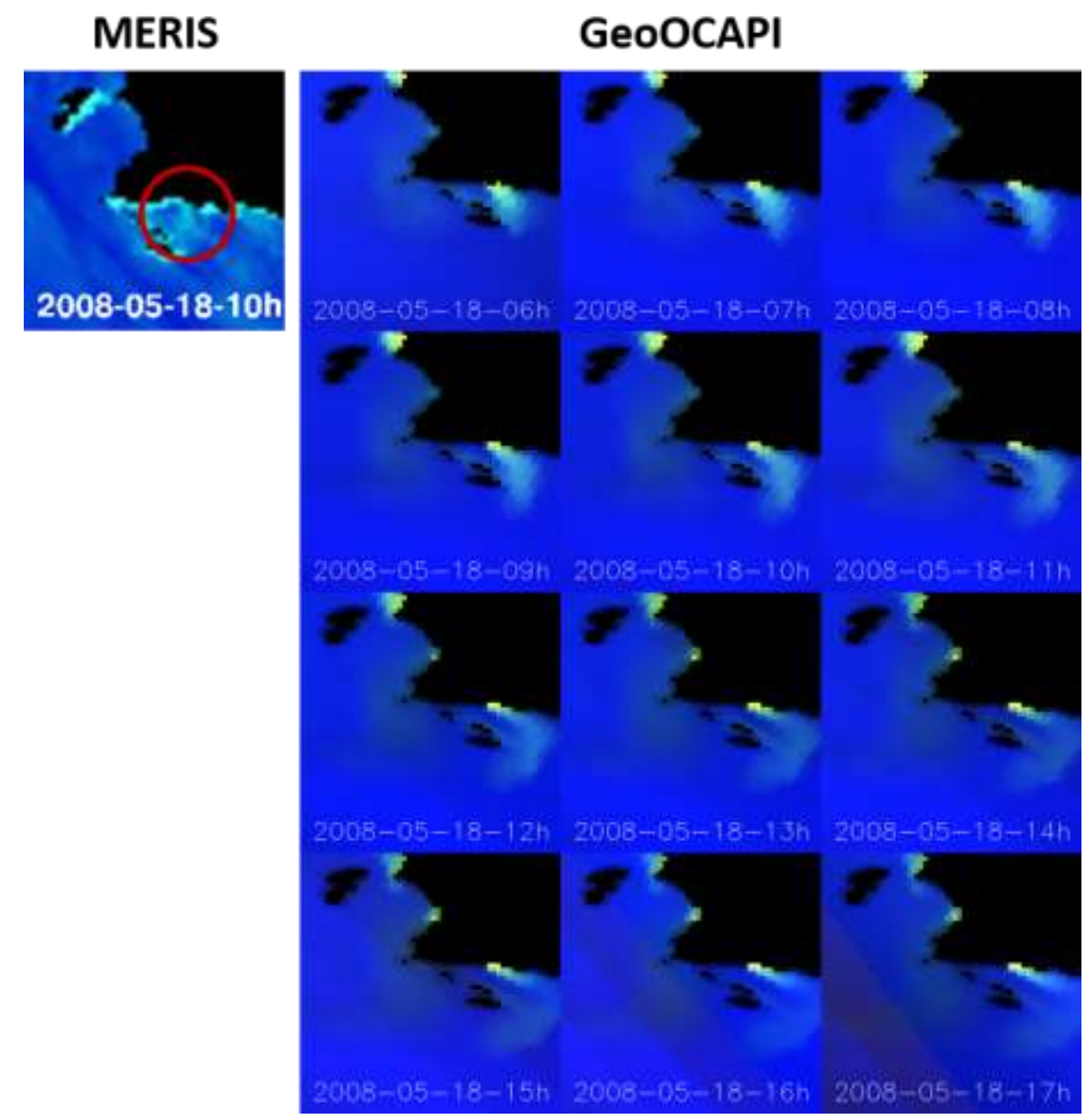

Figure 8. Comparison of color composite images provided by MERIS (10:00) and GeoOCAPI during 1 day (18 may 2008). 

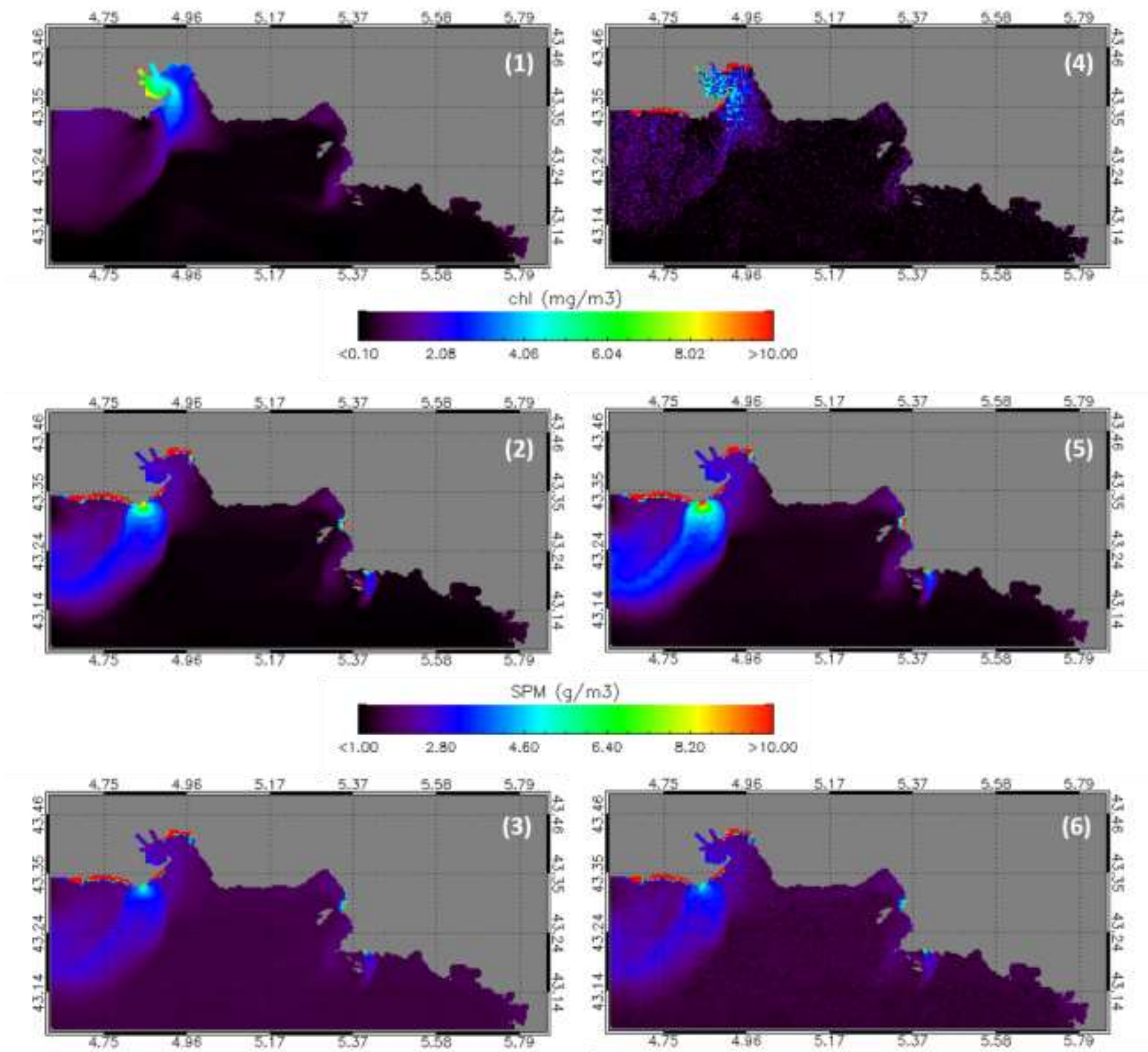

$\operatorname{CDOM}(m-1)$

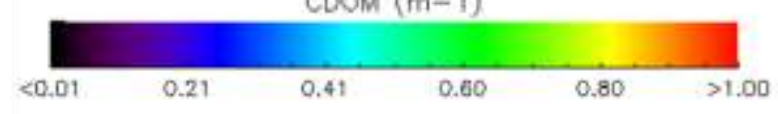

Figure 9. Original chl (1), SPM (2), CDOM (3) maps at 10:00 on May 18, 2008 and the retrieved $\operatorname{chl}$ (4), $\operatorname{SPM}(5), C D O M(6)$ maps. 

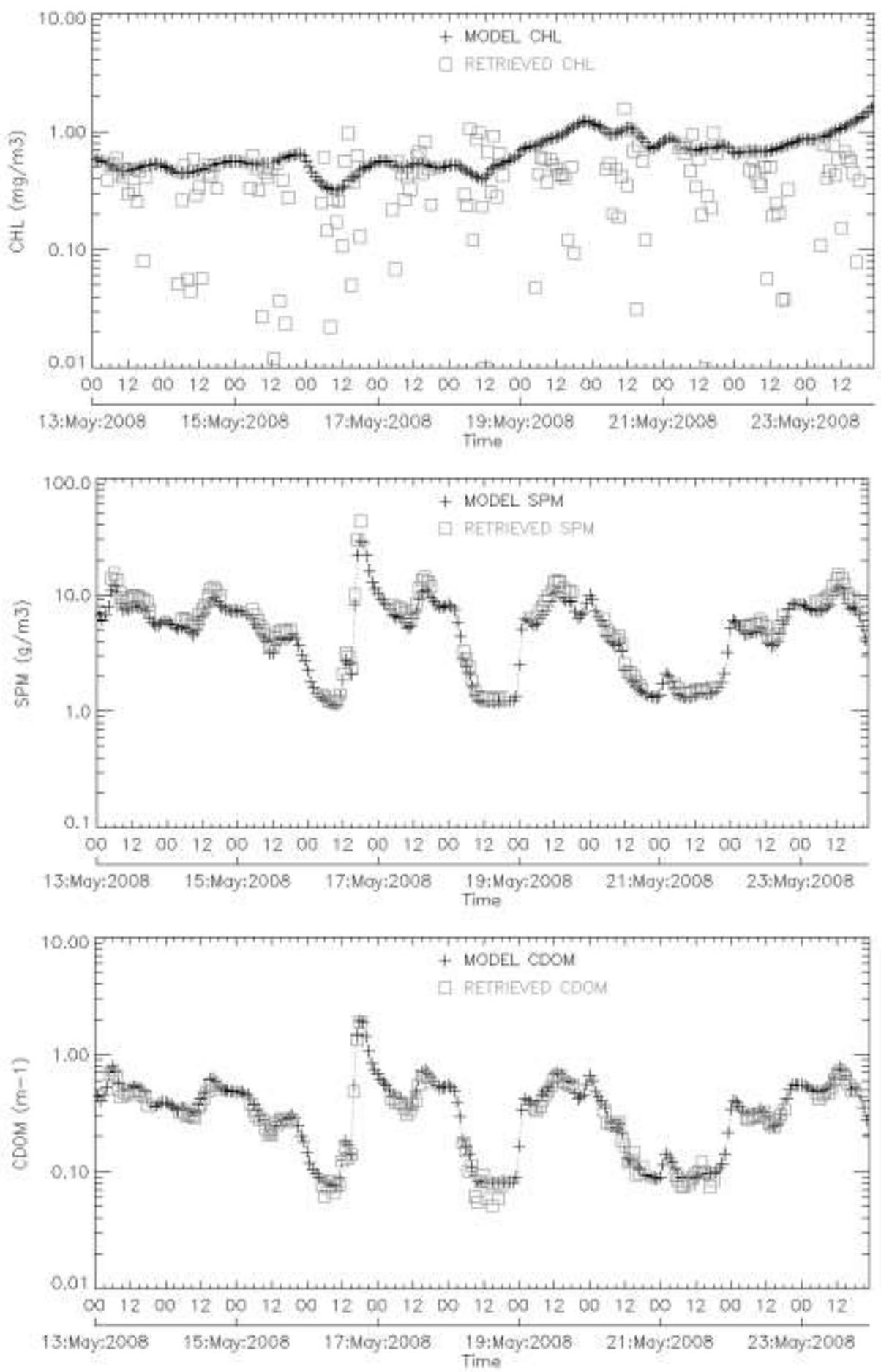

Figure 10. Temporal survey of $\operatorname{chl}\left(\mathrm{mg} \cdot \mathrm{m}^{-3}\right), \operatorname{SPM}\left(\mathrm{g} \cdot \mathrm{m}^{-3}\right)$ and $C D O M\left(\mathrm{~m}^{-1}\right)$ in front of the Cortiou outfall between 13 and 23 May, 2008. The black cross symbols correspond to the profile given by the input models (ME and MS), the retrieved results from simulated GeoOCAPI images between 5:00 and 18:00 are presented by the grey square symbols. 